\title{
PREVALÊNCIA DA DOENÇA DE AUJESZKY NO ESTADO DO PARANÁ NO PERÍODO DE 2000-2009
}

\author{
Aglaci Tomporoski ${ }^{1}$, Geraldo Camilo Alberton ${ }^{2}$, Avani Tomporoski ${ }^{3}$ \\ 1 Secretaria de Estado da Agricultura e do Abastecimento-SEAB - aglacit@gmail.com \\ Universidade Federal do Paraná \\ Engenheira Agronôma
}

RESUMO: A doença de Aujeszky (DA) ou pseudoraiva é uma enfermidade causada pelo Herpesvirus suis. Esta doença afeta grande número de espécies animais e, na suinocultura, possui especial relevância sanitária e econômica. O presente trabalho teve como objetivo demonstrar a prevalência de DA em granjas de reprodutores suídeos certificadas (GRSC), granjas comerciais de suínos (GS), granjas de javalis (JA) e criações de subsistência (CS) no estado do Paraná no período de 2000 a 2009. O estudo foi realizado pela Secretaria de Estado da Agricultura e do Abastecimento (SEAB) do Paraná e foi divido em três etapas: 1) Monitoria sorológica de GRSC no período de 2000 a 2009; 2) Inquérito soroepidemiológico para DA em 283 municípios do estado no ano de 2003; 3) Avaliação dos surtos de DA ocorridos no período de 2000 a 2009. O estudo demonstrou que houve 21 focos de DA no período 2000-2009, sendo 10 constatados a partir de notificação de suspeita da doença. Destes, cinco ocorreram em GS e cinco em CS. No inquérito soroepidemiológico, constatouse 11 focos em 10 municípios, sendo dois em granjas de JA e nove em CS. Em todos os focos de DA foram adotadas medidas sanitárias de saneamento. Conclui-se que a prevalência de DA no estado do Paraná no período de 2000 a 2009 foi de 21 focos, com predomínio em granjas de javalis e em criações de subsistência.

Palavras-chave: javali; herpes vírus suíno; pseudoraiva; suínos

\section{AUJESZKY'S DISEASE PREVALENCE IN PARANA STATE BETWEEN 2000 AND 2009}

ABSTRACT: Aujeszky's disease (AD) or pseudorabies is caused by a porcine herpesvirus type 1 (HSV-1). AD affects many species of animals and acquires special importance in pigs economic and health. The aim of this study was to demonstrate the prevalence of $A D$ in certified pig-breeding farms (GRSC), commercial farms (GS), herds of wild boars (JA) and subsistence farms (CS) in the Parana state. The study was conducted by Secretaria de Agricultura e do Abastecimento (SEAB-PR) and was divided in 3 stages: 1) GRSC serologic monitoring during 2000 to 2009, 2) Seroepidemiological survey in 283 counties in 2003,3) Evaluation of reported outbreaks in the period of 2000-2009. The study showed that there were 21 outbreaks of AD in the period 2000-2009, 10 were identified after disease notification. Out of these 10,5 occurred in the GS and 5 in CS. Seroepidemiological survey showed 11 outbreaks in 10 counties, 2 in the JA e 9 in CS. Sanitary measures were adopted in all outbreaks. We conclude that the prevalence of DA in Parana state was 21 outbreaks, predominantly in wild boar farms and subsistence farms.

Key Worde: HSV-1; pseudorabies; swine; wild boar 


\section{INTRODUCÃO}

A doença de Aujeszky, também conhecida como pseudoraiva, paralisia bulbar infecciosa e peste de coçar, é causada por um vírus cujo agente faz parte da família Herpesviridae, subfamília Alphaherpesvirinae, (Allepuz et al., 2008). Afeta principalmente suínos, ou seja, animais do gênero Sus scrofa domesticus (suíno) e Sus scrofa scrofa (javali europeu) (MAPA, 2007). Esta doença causa graves prejuízos econômicos em diversas fases da produção, ocasionando elevada taxa de mortalidade, principalmente em leitões de maternidade, problemas respiratórios e reprodutivos e queda de desempenho em suínos na fase de crescimento e terminação (Stepan et al., 2003). A DA está difundida em quase todo o mundo, inclusive no Brasil (Cândido et al., 2000; Piatti et al., 2001).

A DA faz parte da lista de doenças de notificação obrigatória da Organização Mundial de Saúde Animal (OIE, 2010). A primeira notificação de DA no Brasil ocorreu em 1932 (Vidor, 1988) e, desde 1934, por meio do Decreto no 24.548, a DA é uma enfermidade de notificação obrigatória no Brasil, e passível de medidas de Defesa Sanitária Animal (Brasil, 1934).

A vigilância para a DA deve ser realizada de forma ativa e passiva. A vigilância passiva fundamenta-se na suspeita da doença e envolvem notificações, visitas de fiscalização e diagnóstico laboratorial. A vigilância ativa, realizada pelo sistema de defesa sanitária, compreende a detecção da doença por meio de identificação das propriedades e áreas de risco, monitoração sorológica de áreas/subpopulações de risco, visitas aos abatedouros, frigoríficos e propriedades, controle e fiscalização sanitária em pontos de concentrações de animais, controle e fiscalização de trânsito de suínos (MAPA, 2007).

Devido à importância da suinocultura para 0 Brasil e considerando os impactos econômicos, sanitários e ambientais envolvidos quando há ocorrência de DA em rebanhos suínos, o presente trabalho tem como objetivo demonstrar a prevalência da doença de Aujeszky no estado Paraná no período de 2000 a 2009.

\section{MATERIAL E MÉTODOS}

O estudo foi realizado pela Secretaria de Estado da Agricultura e do Abastecimento (SEAB) e foi divido em três etapas: 1) Avaliação de granjas de reprodutores suídeos certificadas (GRSC) no período de 2000 a 2009; 2) Inquéritos soroepidemiológico em 2003; 3) Vigilância passiva no período de 2000 a 2009.

1) Avaliação de granjas de reprodutores suídeos certificadas monitorias de GRSC: o estudo das GRSC foi realizado a partir dos dados das monitorias sanitárias de rotina previstas na IN 19/02 do Ministério da Agricultura, Pecuária e Abastecimento (MAPA, 2002). Estas granjas são monitoradas sorologicamente a cada seis meses para a DA. No período compreendido pelo estudo, o número de GRSC no estado do Paraná oscilou de 50 a 60 granjas, sendo que todas foram examinadas no período. O tamanho amostral seguiu o recomendado pela IN 19/02 (MAPA, 2002).

2) Inquérito soroepidemiológico em 2003: foi realizada amostragem de soro de suínos domésticos e de javalis de propriedades localizadas no estado do Paraná. A escolha das propriedades, bem como dos animais que foram amostrados, foi aleatória, por meio de 
sorteio. O estudo amostral trabalhou com nível de confiança de 95\%, especificidade de $100 \%$ e sensibilidade de 95\%, tanto para avaliação da presença de infecção entre granjas como nas matrizes presentes nas mesmas. O período de colheita de amostras e análises foi outubro e novembro de 2003. As granjas foram estratificadas de acordo com os seguintes tipos de produção:

a) Granjas de Suínos (GS): as GS são consideradas propriedades de suínos cadastradas junto ao serviço veterinário oficial, de característica comercial, que apresentaram estrutura física adequada ao tipo de exploração, com manejo, alimentação, condições higiênico-sanitárias satisfatórias e assistência médica veterinária permanente ou eventual. Podem ser granjas de ciclo completo, unidades produtoras de leitões e granjas de terminação. Para distribuição das amostras, as granjas foram agrupadas de acordo com o número de matrizes em: granjas com 1 a 5; 6 a 25; 26 a 100; 101 a 500 e, com mais de 500 matrizes.

b) Granjas de Javalis (JA): as JA são granjas destinadas a criação de javalis. Foram amostradas todas as propriedades de javalis cadastradas junto à defesa sanitária animal (DSA) no estado do Paraná.

c) Criatórios de Suínos (CS): os CS são propriedades de subsistência ou criatórios de suínos de "fundo de quintal" ou "caseiras", que produzem para consumo próprio ou têm alcance local, sem característica comercial. Para distribuição das amostras foi utilizado como referência o cadastro atualizado de propriedades com bovinos do estado do Paraná, uma vez que, na grande maioria destas propriedades, há criação de suínos para consumo próprio, sem fins comerciais.

3) Vigilância passiva: realizou-se um estudo documental de todas as atuações da SEAB-PR nos casos de suspeita e de focos confirmados da doença no período de 2000 a 2009. No registro de cada foco havia informações relevantes como por exemplo a origem da notificação, o tipo de criação, número de animais na propriedade, número de animais afetados, sinais clínicos e o histórico recente de movimentação de animais.

Em todas as etapas a colheita de amostras foi realizada por médicos veterinários da Secretaria de Estado da Agricultura e do Abastecimento (SEAB) do Departamento de Fiscalização e Defesa Agropecuária (DEFIS) da Divisão de Defesa Sanitária Animal (DDSA). O sangue foi colhido por punção venosa, sem anticoagulante, e transferido para tubos apropriados. Após a coagulação sanguínea as amostras foram centrifugadas a $358.4 \mathrm{~g}$ durante 10 minutos. Os soros foram enviados sob refrigeração para 0 laboratório, acompanhados de formulário de colheita de amostras incluindo dados da propriedade e do rebanho (Rachel, 2003). No laboratório as amostras foram armazenadas à temperatura de $-20^{\circ} \mathrm{C}$ até o seu processamento.

Os exames sorológicos foram realizados no Laboratório Marcos Enrietti, laboratório oficial do Estado do Paraná. A pesquisa de anticorpos contra a DA foi realizada pelo teste de soroneutralização, segundo as normas do "Manual of Standards for Diagnostic Tests and Vaccine" (OIE, 2008).

O número de animais e de granjas positivas para DA entre os diferentes tipos de granjas (CS, GS e JA) foram comparados entre si pelo Teste Exato de Fisher, sendo considerados significativos valores de $\mathrm{P}$ menor ou igual a 0,05.

\section{RESULTADOS}

No período de 2000 a 2009 foram identificados 21 focos de doença de Aujeszky (Tabela 1), sendo 11 por 
vigilância ativa (inquérito soroepidemiológico) (Tabela 2) e 10 por vigilância passiva (Tabela 3). Nenhum foco foi identificado nas monitorias de GRSC. Dos 21 focos, 5 (23\%) foram em granjas tecnificadas (GS), 2 (1\%) em granjas de javalis e, 14 (66\%) em criatórios de suínos.

Tabela 1. Focos da Doença de Aujeszky no Período de 2000 a 2009 no estado do Paraná, Brasil

\begin{tabular}{cc}
\hline ANO & NÚMERO DE FOCOS \\
\hline 2000 & 4 \\
2001 & 3 \\
2002 & 0 \\
2003 & 14 \\
2004 a 2009 & 0 \\
\hline Total & 21 \\
\hline
\end{tabular}

No inquérito soroepidemiológico realizado em 2003, 11 propriedades tiveram diagnóstico positivo para DA, das quais nove foram classificadas como criatórios de suínos (CS) e duas como estabelecimento de criação de javalis (JA). Proporcionalmente, o número de animais e de granjas de positiva para a DA não diferiu $(P>0,05)$ entre os tipos CS $X$ JA, mas diferiu $(P<0,05)$ entre os tipos GS $X$ JA e GS $X$ CS. Todos os focos identificados foram saneados.

\section{DISCUSSÃO}

O Brasil é o quarto maior produtor de suínos do mundo com um rebanho de 37 milhões de cabeças, sendo que o estado do Paraná é o terceiro maior produtor do país (SEAB, 2010). Deste modo, o número de focos identificados no período de 2000 a 2009 é pequeno, com uma incidência esporádica da doença, sendo que no período de 2004 a 2009, a incidência foi nula. Situação diferente desta era a do estado de Santa Catarina, que é o maior produtor de suínos do Brasil. Neste estado, a DA era considerada endêmica, sendo que em 2001 haviam 320 granjas infectadas. Após a aplicação de um programa de erradicação iniciado em 2001, a doença foi erradicada do estado (EMBRAPA, 2005).

A inexistência de DA nas GRSC demonstra que as medidas de biossegurança determinadas pela IN 19/02 MAPA têm sido efetivas para manter estes rebanhos livres desta doença. De acordo com Zanella et al.(2008) e Embrapa (2005), a introdução de reprodutores contaminados é a forma de maior difusão da DA e, neste contexto, a regulamentação das granjas de reprodutores de suínos no Brasil, que iniciou-se em 1984 com a inclusão de monitoria para DA em reprodutores em granjas certificadas, por meio da IS $\mathrm{n}^{-}$ 02/84 (MAA, 1984) e posteriormente com implementação de GSMD (Granja de Suínos com o Mínimo de Doenças ) em 1992 (MARA, 1992), trouxe um grande incremento sanitário para o país, fazendo que doenças como a de Aujeszky deixassem de ser transmitidas por reprodutores oriundos de GRSC. Nas criações de subsistência, é provável que os reprodutores não sejam adquiridos de GRSC. Deste modo, nestes tipos de criação de baixa tecnificação, o risco de introdução de doenças é maior, o que pode ser comprovado neste estudo, pois $66 \%$ dos focos foram em criatórios de suínos. O risco de introdução de DA com reprodutores também é elevado nas granjas de javalis, pois no Brasil não existe nenhuma GRSC de javalis. Sendo assim, os criadores acabam adquirindo animais de granjas não certificadas, aumentando 0 risco de difusão de doenças.

Nos 11 focos demonstrados pelo inquérito soroepidemiológico os suínos não apresentavam sinais clínicos, e, isto pode ser devido três possibilidades: infecção subclínica; infecção crônica; ou - estabelecimento da principal característica da doença de Aujeszky 
Tabela 2. Resultados do Teste de Soroneutralização para a Doença de Aujeszky (DA) em Inquérito Soroepidemiológico no estado do Paraná, ano de 2003

\begin{tabular}{lcccc}
\hline TIPO DE CRIAÇÃO & \multicolumn{2}{c}{ NÚMERO DE PROPRIEDADES } & \multicolumn{2}{c}{ NÚMERO DE ANIMAIS } \\
\cline { 2 - 5 } & Amostradas & Positivas & Amostrados & Positivos \\
\hline Granja de Suínos & 320 & 0 & 3968 & 0 \\
Granja de Javalis & 13 & 2 & 135 & 3 \\
Criatório de suínos & 320 & 9 & 1335 & 17 \\
Total & 653 & 11 & 5438 & 20 \\
\hline
\end{tabular}

Tabela 3. Focos de Doença de Aujeszky (DA) identificados por vigilância passiva no período de 2000 a 2003 no estado do Paraná

\begin{tabular}{ccccc}
\hline TIPO DE CRIAÇÃO & N $^{\circ}$ DE & \multicolumn{3}{c}{ NÚNERO TOTAL DE ANIMAIS } \\
\cline { 2 - 5 } & PROPRIEDADES & Existentes & Enfermos & Sacrificados/abatidos \\
\hline Granja de suínos & 05 & 9171 & 572 & $6358^{*}$ \\
Criatório de Suínos & 05 & 140 & 14 & $140^{*}$ \\
\hline
\end{tabular}

A diferença entre número de animais existentes e abatidos corresponde ao número de animais negativos para DA no exame sorológico, que permaneceram na propriedade para posterior abate em matadouro inspecionado.

que é a latência, estado no qual o vírus não provoca sinais clínicos, mas persiste indefinidamente no animal infectado (Echeverría e Nosseto, 2000). Após estimulação específica, o vírus em estado de latência pode ser reativado e excretado para 0 meio ambiente, difundindo e infectando os animais susceptíveis (Vieira e Vannier, 2002). Estas características da DA, dificultam o trabalho da Defesa Sanitária Animal, pois ela atua principalmente com vigilância passiva, atendendo notificações de suspeitas de doença. Se a doença não produzir quadro clínico, como nos 11 focos identificados, este tipo de vigilância não os identifica, possibilitando a perenização dos focos. Conforme pôde ser verificado nos resultados desta pesquisa, a vigilância ativa foi mais eficaz que a vigilância passiva, visto que em nove anos de vigilância passiva constataram-se 10 focos de DA e, em apenas um inquérito soroepidemiológico, identificou-se 11 focos.

As categorias de importância para o agronegócio do estado são as granjas comerciais (GS) e as granjas de reprodutores suídeos certificadas
(GRSC), que quando da realização do inquérito soroepidemiológico não apresentaram atividade viral para DA. O status sanitário destas granjas é conseqüência do desenvolvimento e implantação de normas rígidas para proteger o rebanho de suínos contra a introdução e disseminação de agentes infecciosos (MAPA, 2002; Meyer e Sobestiansky, 2005). Porém, por mais rigorosas que sejam as medidas de proteção adotadas por um país, região ou zona livre de uma doença, não é possível ter garantia absoluta da não introdução ou reintrodução do agente infeccioso (MAPA 2004; Davies; 2007). Atualmente, em decorrência de avanços tecnológicos e ampliação das redes comerciais, intensificou-se o trânsito de pessoas, animais, materiais de reprodução animal, produtos e subprodutos de origem animal, aumentando, também, o risco de disseminação de doenças, ou seja, mesmo que a DA ocorra em áreas remotas, 0 vírus pode alastrar-se para outras regiões, caso não exista um controle adequado e efetivo (Sobestiansky et al., 2001; Souza et al., 2002). 
Quanto à condição epidemiológica praticamente independente entre os tipos de produção (GS, JA e CS), a Organização Mundial de Saúde Animal (OIE) não considera compartimentalização de tipos de produção. Para a OIE (2009) o reconhecimento de subpopulações animais de distintos status sanitário se baseia na regionalização/zonificação conforme fronteiras geográficas, ou seja, somente é considerado como área livre ou zona livre para DA, quando são obtidos resultados negativos de uma amostra representativa de todos os tipos de produção. Assim, os tipos de produção GRSC, GS, JA e CS não podem ser analisados isoladamente, e o estado, área ou país não pode ser considerado como livre de DA.

Embora haja legislação recente pelo MAPA, IN 8 (MAPA, 2007) que estabelece as normas para o controle e erradicação da doença de Aujeszky, ainda não houve adesão ao programa de controle e erradicação de DA por parte dos estados. É urgente que os estados, respeitadas as suas particularidades, realizem esforços conjuntos para execução de medidas necessárias ao controle e erradicação de doença de Aujeszky no Brasil.

\section{CONCLUSÃO}

A prevalência de doença de Aujeszky no estado do Paraná no período de 2000 a 2009 foi de 21 focos, sendo que todos foram saneados. A doença teve maior prevalência em granjas de javalis e em criações de subsistência.

\section{AGRADECIMENTOS}

Aos médicos veterinários das unidades veterinárias locais da Secretaria da Agricultura e do Abastecimento do estado do Paraná, aos supervisores técnicos regionais; as médicas veterinárias do Centro de Diagnóstico Marcos Enrietti

\section{REFERÊNCIAS}

ALLEPUZ, A.; SAEZ, M.; ALBA, A. et al. Exploratory spatial analysis of Aujeszkys disease during four phases of eradication programme in Catalonia, Spain (2003-2007). Preventive Veterinary Medicine, v.86, p.164-175, 2008.

BRASIL. Regulamento da Defesa Sanitária Animal. Decreto 24-548, 03/jul. Publicado no Diário Oficial da União de 14/07/1934.

CÂNDIDO, A.L.; RESENDE, M.; OLIVEIRA, M.E. et al. Partial characterization of a Brazilian strain of Aujeszky's disease vírus recovered from a pig with subclinical infection. Arquivo Brasileiro de Medicina Veterinária e Zootecnia, v.52, n.4, p.295-301, 2000.

DAVIES, P.R. Old diseases, emergent diseases: the evolution of helth in the swine industry. In: CONGRESSO BRASILEIRO DE

VETERINÁRIOS ESPECIALISTAS EM SUÍNOS, 13., Florianópolis, 2007. Anais... Florianópolis, Associação Brasileira de Veterinários Especialistas em Suínos, 2007. p.75-86.

ECHEVERRÍA, M.G.; NOSETTO, E.O.

Actualización enfermedad de Aujeszky. Analecta Veterinária, v.20, n.2, p.22-30, 2000.

EMPRESA BRASILEIRA DE PESQUISA AGROPECUÁRIA - EMBRAPA. Centro Nacional de Pesquisa de Suínos e Aves. Programa de

Erradicação da Doença de

Aujeszky no Estado de Santa Catarina.

Concórdia, SC, 2005. Circular Técnica 44. 8p.

MINISTÉRIO DA AGRICULTURA E

ABASTECIMENTO - MAA. Instrução de Serviço $\mathrm{n}^{\circ} 02$, de 17 de abril de 1984. Diário Oficial da República Federativa do Brasil, Brasília, DF, 17 abr. 1984. Seção 1. p.4

MINISTÉRIO DA AGRICULTURA PECUÁRIA E DO ABASTECIMENTO - MAPA. Instrução Normativa $n^{\circ} 19$. Diário Oficial da República Federativa do Brasil. Brasília, DF, 15 fev. 2002. n’. 41. Seção 1. p. 3.

MINISTÉRIO DA AGRICULTURA PECUÁRIA E DO ABASTECIMENTO - MAPA. Instrução Normativa $n^{\circ} 27$. Diário Oficial da República Federativa do Brasil. Brasília, DF, 20 abr. 2004. no. 79. Seção 1. p. 7

MINISTÉRIO DA AGRICULTURA PECUÁRIA E DO ABASTECIMENTO - MAPA. Instrução 
Normativa $n^{\circ} 8$, Diário Oficial da República Federativa do Brasil. Brasília, DF, 03 abr. 2007. №. 68. Seção 1. p. 1

MINISTÉRIO DA AGRICULTURA E REFORMA AGRÁRIA - MARA. Instrução Operativa oㅡ 001. Diário Oficial da Republica Federativa do Brasil. Brasília, DF, 26 mar. 1992. Seção 1. p. 3.

MEYER, F.; SOBESTIANSKY, J.

Biossegurança, aspectos relacionados na transmissão de doenças. In: SIMPÓSIO GOIANO DE AVICULTURA, 7., Goiânia, 2005. Anais... Goiânia: CBNA, 2005. p.27-31.

PIATTI, R.M.; IKUNO, A.A.; CUNHA, E.S. et al. Caracterization of Aujeszky's disease virus isolates from south and southeast Brazil by RFLP analysis. Microbiology, v.32, n.2, p.144-146, 2001.

RACHEL, G.M.E. Monitoramento sorológico da brucelose e da doença de Aujeszky em suíno no estado de Mato Grosso do Sul. 2003. Campo Grande, 78f. Dissertação (Mestrado em Produção e Gestão Agroindustrial) - Curso de Pós -graduação em Ciências Veterinárias, Universidade para o Desenvolvimento do Estado e da Região do Pantanal.

SECRETARIA DE ESTADO DA AGRICULTURA E DO ABASTECIMENTO - SEAB, Departamento de Economia Rural, Suinocultura, abril de 2010.

SOBESTIANSKY, J.; CAIADO, K.L.; SOUZA, A.S. et al. Doença de Aujeszky: estudo sorológico da infecção pelo virus em suínos criados em sistema extensivo em promiscuidade com bovinos no estado de Goiás. In: CONGRESSO DE VETERINÁRIOS ESPECIALISTAS EM SUÍNOS, 10., Porto Alegre, 2001. Anais... Porto Alegre: Associação Brasileira de Veterinários Especialistas em Suínos, 2001. p 91-92.

SOUZA, C. M.; SOBESTIANSKY, J., MATOS, M.P.C. et al. Prevalência da Infecção pelo vírus da doença de Aujeszky em matrizes de sistema de produção que abastecem o mercado consumidor de Goiânia. Ciência Animal Brasileira, v.3, n.2, p.53-56, 2002
STEPAN, A.L.S.; STOLL,P.A.; GROFF, F.H.S. Sorologia Perifocal para Estudo da Ocorrência da Doença de Aujeszky em Propriedade no Rio Grande do Sul. In: CONGRESSO DE

VETERINÁRIOS ESPECIALISTAS EM SUÍNOS, 11., Goiânia, 2003. Anais... Goiânia: UFG, 2003. p.115-116.

VIEIRA, R.P.; VANNIER, P. A doença de Aujeszky. In: VIEIRA, R.P.; VANNIER, P.; SILVEIRA, D.; SOBESTIANSKY, J.; VIEIRA, $H$. P.; GOURREAU, J.M. Doença de Aujeszky. In: Manual de Práticas Veterinárias. 1 ed. Lisboa: Fundação Calouste Gulbenkian, 2002. p.7-143.

VIDOR, T. Doença de Aujeszky etiopatogenia e controle. Hora Veterinária, v.43, p.47-52, 1988.

WORLD ORGANISATION FOR ANIMAL HEALTH - OIE [2008]. Manual of Standards Diagnostic Tests and Vaccines. Disponível em: <http://www.oie.int/eng/normes/mmanual/2008/p df/2.01.02_AUJESZKYS_DIS.pdf>. Acesso em 06/04/2010.

WORLD ORGANISATION FOR ANIMAL HEALTH - OIE [2009]. Terrestrial Animal Health Code. Disponível em:

$<$ http://www.oie.int/eng/normes/mcode/en_INDE X.HTM>. Acesso em 06/04/2010.

WORLD ORGANISATION FOR ANIMAL HEALTH - OIE. [2010]. Animal Disease diseases notifiable to the OIE. Disponível em: $<$ http://www.oie.int/eng/maladies/en_classificatio n2010.htm?e1d7>. Acesso em 06/04/2010.

ZANELLA, J.R.C.; AMARAL, A.L.; VENTURA, L.V. et al. Erradicação da doença de Aujeszky em Santa Catarina: importância da condição sanitária das leitoas de reposição. Ciência Rural, v.38, n.3, p.1-8, 2008. 